\title{
Nocebo effects by providing informed consent in shared decision making? Not necessarily: a randomized pilot-trial using an open-label placebo approach
}

\author{
Fabian Holzhüter * (D) and Johannes Hamann
}

\begin{abstract}
Background: Thorough information of the patient is an integral part of the process of shared decision making. We aimed to investigate if detailed information about medication may induce nocebo (or placebo) effects.

Methods: We conducted a randomized, single-blind, pilot-study including $n=51$ psychiatric in-patients aged between 18 and 80 years with a depressive disorder and accompanying sleeping disorders. In the intervention group we provided thorough information about adverse effects, while the control group received only a simple consent procedure. In both groups, patients received an open-label placebo pill instead of their sleeping medication.

Results: No statistically significant differences between the intervention group and the control group were found regarding the main outcome parameter (a visual analogue scale indicating impairment by the new pill).

Conclusion: In this study, we were not able detect an effect of informed consent vs. simple consent on the emergence of placebo or nocebo effects. This finding is contrary to most assumptions and publications about this topic.
\end{abstract}

Trial registration: Trial registration number: DRKS00017653, registered August 30th 2018. Retrosprectively registered.

Keywords: Informed consent, Simple consent, Nocebo, Placebo, Shared decision making, Open-label placebo

\section{Strengths and limitations of this study}

- We performed an experimental randomized clinical trial with high clinical relevance.

- This study investigated a field of medicine that is lacking further research.

- There are weaknesses in the study design (e.g. a small number of participants).

- Open-label placebo is an under-researched topic in medicine [1]

\footnotetext{
* Correspondence: fabian.holzhueter@mri.tum.de

Klinik und Poliklinik für Psychiatrie und Psychotherapie, Klinikum rechts der Isar, Technische Universität München, Möhlstraße 26, 81675 Munich, Germany
}

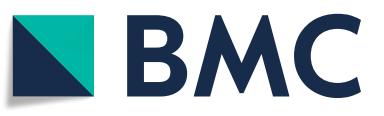

(c) The Author(s). 2020 Open Access This article is licensed under a Creative Commons Attribution 4.0 International License, which permits use, sharing, adaptation, distribution and reproduction in any medium or format, as long as you give appropriate credit to the original author(s) and the source, provide a link to the Creative Commons licence, and indicate if changes were made. The images or other third party material in this article are included in the article's Creative Commons licence, unless indicated otherwise in a credit line to the material. If material is not included in the article's Creative Commons licence and your intended use is not permitted by statutory regulation or exceeds the permitted use, you will need to obtain permission directly from the copyright holder. To view a copy of this licence, visit http://creativecommons.org/licenses/by/4.0/ The Creative Commons Public Domain Dedication waiver (http://creativecommons.org/publicdomain/zero/1.0/) applies to the data made available in this article, unless otherwise stated in a credit line to the data. 
It has been postulated that placebo and nocebo effects may occur in the context of SDM [12, 13], still, to our best knowledge, there exist no clinical trials concerning this issue in mental health [1].

The aim of the present study was to investigate information provision as an important aspect of SDM with respect to potential nocebo effects.

\section{Methods}

This study was a prospective, randomized, single-centered, subject-blind pilot study. We compared informed consent with simple consent about sleep medication for in-patients with depressive disorders. The Ethical Review Board of the Medical Faculty of the Technical University of Munich approved the study protocol (5708/13).

We recruited in-patients from one psychiatric university hospital in Germany and included female and male inpatients, aged between 18 and 80 years, diagnosed with a depressive disorder (ICD-10: F31, F32, F33, F41.2). Participants needed to be on medication for a documented sleep disorder.

For all patients, regular sleeping medication was paused for one night and replaced by a placebo pill in order to standardize drug effects between groups. Before obtaining written consent from the patients, we handed out an information sheet about our study. In this context, we explained to the patients that instead of their usual sleeping pill, they would receive a sham medication, known as placebo, which does not contain any active component. We also explained to the patients, that based on other scientific studies, placebos can have positive effects and that similar mechanisms are activated in the body as by regular medication. Thus, we performed an open-label placebo approach [14, 15]. Other studies found evidence that an open-label placebo administration was superior to notreatment or treatment as usual [16, 17]. After patients filled out our baseline questionnaire, we used the phrasing "new sleeping pill" in order to remind the patients they'll receive their placebo in the evening (see Table 1).

We used a white placebo pill $(7 \mathrm{~mm})$ containing lactose monohydrate, cellulose powder, magnesium stearate and microcrystalline cellulose.

In the intervention group (informed consent) we gave detailed information on nonspecific side-effects that may be caused by open-label placebo (i.e. dryness of the mouth, vertigo and sweating, [18]), while in the control group (simple consent) we only informed the patients shortly about receiving a new sleeping pill (Table 1).

After enrolment and written consent, patients completed the first questionnaire. Right afterwards, patients were included to the intervention or control group, using a randomization list. From this moment on, the investigator was un-blinded and started the standardized informative conversation (see Table 1). In the same evening, patients received the placebo instead of their regular sleep
Table 1 Intervention and control condition

\begin{tabular}{|c|c|}
\hline Control & Intervention \\
\hline simple consent & informed consent \\
\hline \multirow[t]{2}{*}{$\begin{array}{l}\text { Dear Mrs. / Mr. [, just as we } \\
\text { discussed earlier, you will receive } \\
\text { a new sleeping pill for tonight. }\end{array}$} & $\begin{array}{l}\text { Dear Mrs. / Mr. Q, just as we } \\
\text { discussed earlier, you will receive } \\
\text { a new sleeping pill for tonight. }\end{array}$ \\
\hline & $\begin{array}{l}\text { Before that, I would like to give } \\
\text { you some more information about } \\
\text { that drug. } \\
\text { The sleeping pill improves falling } \\
\text { asleep and sleeping through the } \\
\text { night in about } 60 \% \text { of all patients. } \\
\text { It does not work for about } 40 \% \text { of } \\
\text { all patients. } \\
\text { No serious side effects are to be } \\
\text { expected, but of course, like in all } \\
\text { other medicaments, side effects } \\
\text { can occur. About those, I would } \\
\text { like to give you some more } \\
\text { information: } \\
\text { Around } 30 \% \text { of all patients report } \\
\text { dry mouth. } \\
\text { Around } 27 \% \text { of all patients report } \\
\text { slight vertigo. } \\
\text { About } 40 \% \text { of all patients report } \\
\text { increased sweating. }\end{array}$ \\
\hline $\begin{array}{l}\text { As usual, you will be given that } \\
\text { pill about half an hour before } \\
\text { going to bed. Tomorrow, we } \\
\text { will hand out a questionnaire } \\
\text { to you, in which you can } \\
\text { indicate how you have been } \\
\text { sleeping tonight. }\end{array}$ & $\begin{array}{l}\text { As usual, you will be given that pill } \\
\text { about half an hour before going to } \\
\text { bed. Tomorrow, we will hand out a } \\
\text { questionnaire to you, in which you } \\
\text { can indicate how you have been } \\
\text { sleeping tonight. }\end{array}$ \\
\hline
\end{tabular}

medication. In the next morning, each patient had to fill out the second questionnaire.

At baseline, we obtained patients' socio-demographics and asked for specifications about the sleeping disorder, such as the frequency of sleep disturbances in the last 7 days, whether the patient suffered from sleep-onset insomnia, sleep-maintenance insomnia or combined, the satisfaction with the sleep condition and the satisfaction with the treatment of the sleeping disorder.

The day after, patients provided a detailed, subjective rating of the last night's sleep (Table 2) including a visual analogue scale (main outcome parameter) indicating how impaired they felt by their sleep medication.

The questionnaires were based on validated measures and additional specific questions. For the validated measures we referenced the respective literature [19-21]. A translation of the additional questions is attached.

Statistical analyses were conducted with SPSS $^{\circ}$ Version 24. Descriptive statistic included frequencies and means. For group comparisons we used $\mathrm{t}$-test or $\chi^{2}$-test. A $p$ value $<0.05$ was defined as statistically significant.

\section{Patient and public involvement}

No patient involved. 
Table 2 Outcomes

\begin{tabular}{|c|c|c|c|}
\hline & intervention & control & $p$-value \\
\hline $\begin{array}{l}\text { "Please indicate how much you have felt impaired by side effects" } \\
\text { (main outcome) } \\
\text { (1 "not at all" - } 10 \text { "very much") }\end{array}$ & $1.5( \pm 1.4)$ & $2.8( \pm 3.0)$ & $p=0.06$ \\
\hline $\begin{array}{l}\text { "How well did you sleep last night?" } \\
\text { (1 "very bad" - } 5 \text { "very good") }\end{array}$ & $2.4( \pm 1.3)$ & $2.1( \pm 1.2)$ & $p=0.56$ \\
\hline $\begin{array}{l}\text { "How much did the new drug cause side effects?" } \\
(1 \text { "not at all" }-5 \text { "a lot") }\end{array}$ & $1.3( \pm 0.7)$ & $1.6( \pm 1.2)$ & $p=0.23$ \\
\hline $\begin{array}{l}\text { "How satisfied have you been with the new drug?" } \\
\text { (1 "not satisfied at all" - } 5 \text { "very satisfied") }\end{array}$ & $2.0( \pm 1.3)$ & $1.6( \pm 0.8)$ & $p=0.29$ \\
\hline $\begin{array}{l}\text { "How satisfied have you been with the amount of information } \\
\text { about the new drug?" } \\
\text { ( } 1 \text { "not satisfied at all" - } 5 \text { "very satisfied") }\end{array}$ & $4.5( \pm 1.1)$ & $4.4( \pm 1.3)$ & $p=0.76$ \\
\hline $\begin{array}{l}\text { "How recreative was your sleep?" } \\
\text { (1 "very recreative" }-6 \text { "not recreative at all") }\end{array}$ & $4.2( \pm 1.7)$ & $4.2( \pm 1.5)$ & $p=0.98$ \\
\hline Time to fall asleep (min) & $98.9( \pm 88.9)$ & $108.0( \pm 87.4)$ & $p=0.55$ \\
\hline Time spent awake during night (min) & $115.9( \pm 113.2)$ & $120.2( \pm 134.3)$ & $p=0.90$ \\
\hline Time spent sleeping (min) & $306.2( \pm 122.1)$ & $335.0( \pm 157.0)$ & $p=0.47$ \\
\hline Nightmares (Yes) & $15.4 \%(n=4)$ & $16.0 \%(n=4)$ & $p=1.00$ \\
\hline
\end{tabular}

\section{Results}

Altogether 52 patients were recruited and data of 51 patients were analyzed (missing data for one patient). There were 26 patients in the intervention group and 25 patients in the control group. At baseline the two groups did not differ with regard to the patients' age, gender, sleep quality and experience with medication.

The patients' ratings concerning tolerability of the study medication and sleep quality showed no statistical differences between the groups for any outcome (Table 2 ). For the primary outcome (visual analogue scale indicating impairment by side effects) there was a statistical trend towards higher impairment in the control group.

\section{Discussion}

Respectively, we were not able to show differences regarding side-effects and drug-efficacy between patients receiving simple and informed consent. Thus there was no hint towards nocebo (or placebo) effects deriving from the kind of information provision. The statistical tendency towards higher impairment in the control group opposed our presumption that a detailed information may induce side effects in patients.

\section{Limitations}

The total number of 51 patients and the short duration of the intervention might have been too small to detect a possible difference between the two groups. During our conversation with the patient, we mentioned no severe or life-threatening side effects but only those that were likely to occur while taking a placebo pill. Also, the investigator informed the patients and the effects could be maximized by choosing another method or person.
Additionally, one could assume that the open-label placebo approach might have weakened possible effects and that an approach with deception might have maximized the findings [15]. Anyhow, we chose an openlabel placebo approach for different reasons. Aiming to investigate how providing information may induce side effects, we saw no reason to deceive the patient and instead chose the most transparent study design. Since there are positive and negative results in literature for open-label placebo administration, there was no clear argument against it. In fact, our pilot study delivered results that showed no effect of this approach, which might be helpful for future studies.

Furthermore, the open label placebo approach had been highly recommended by our institutional review board.

Also, it is possible to object that the control group did obtain another kind of intervention instead of no treatment or treatment as usual, since all participants received the placebo pill and a short information in terms of simple consent.

\section{Conclusion}

To conclude, we cannot support the assumption that nocebo effects can be induced by the extent of information provision to the patient. Still, there are weaknesses in our study design that may have skewed our findings. Unfortunately, and despite the importance of the topic, there is still a lack of studies focusing on the influences of doctorpatient-relationship on health outcomes. Thus, even though we could neither show a negative nor a positive effect of thoroughly informing the patient, further research is required to integrate our finding in an established concept. Especially as these findings oppose most publications that attribute nocebo effects to informed consent [22, 23]. 
Consequently, we want to encourage physicians to provide thorough information to their patients and not to be reluctant to take this important step of SDM. As implication for clinical practice, the way physicians discuss possible side effects with their patients is subject to an active discussion [24-26]. For example the concept of "contextualized informed consent" proposed by Kaptchuk et al. [27] appears to be a way of respecting patient autonomy and avoiding possible nocebo effects.

For further studies investigating this topic, we recommend measures to increase possible nocebo or placebo effects. Amongst others, this could be an administration with deception or by a person of authority. In addition, a greater study population might be necessary to detect differences between the groups.

\section{Supplementary information}

Supplementary information accompanies this paper at https://doi.org/10. 1186/s12910-020-00541-y.

Additional file 1. CONSORT 2010 Flow Diagram

\section{Abbreviation}

SDM: shared decision making

\section{Acknowledgments}

Not applicable.

\section{CONSORT guidelines}

The study adheres to CONSORT guidelines.

\section{Authors' contributions}

There are no further contributors besides the mentioned authors of this study. $\mathrm{FH}$ recruited the patients and collected data. $\mathrm{FH}$ and $\mathrm{JH}$ analyzed the data and contributed to the manuscript. Both authors read and approved the final manuscript.

\section{Funding}

We did not receive any funding for this study. Open Access funding enabled and organized by Projekt DEAL.

\section{Availability of data and materials}

There is data available concerning the results and questionnaires mentioned. The authors can access this data and it can be obtained from the authors upon reasonable request.

\section{Ethics approval and consent to participate}

Written consent to participate was obtained from study participants. The Ethics Committee of Technical University Munich approved this study.

\section{Consent for publication}

Not applicable.

\section{Competing interests}

There is no conflict of interest we can proclaim.

Received: 12 March 2020 Accepted: 5 October 2020

Published online: 14 October 2020

\section{References}

1. Blease CR, Bernstein MH, Locher C. Open-label placebo clinical trials: is it the rationale, the interaction or the pill? BMJ Evid Based Med. 2019:bmjebm2019-111209..
2. Charles C, Gafni A, Whelan T. Shared decision-making in the medical encounter: what does it mean? (or it takes at least two to tango). Soc Sci Med. 1997;44(5):681-92.

3. Harter M. Shared decision making--from the point of view of patients, physicians and health politics is set in place. Z Arztl Fortbild Qualitatssich. 2004;98(2):89-92

4. Saheb Kashaf M, McGill ET, Berger ZD. Shared decision-making and outcomes in type 2 diabetes: a systematic review and meta-analysis. Patient Educ Couns. 2017:100(12):2159-71.

5. Durand MA, Carpenter L, Dolan H, Bravo P, Mann M, Bunn F, et al. Do interventions designed to support shared decision-making reduce health inequalities? A systematic review and meta-analysis. PLoS One. 2014;9(4):e94670.

6. Protheroe J, Fahey T, Montgomery AA, Peters TJ. The impact of patients preferences on the treatment of atrial fibrillation: observational study of patient based decision analysis. BMJ. 2000;320(7246):1380-4.

7. Drake RE, Deegan PE. Shared decision making is an ethical imperative. Psychiatr Serv. 2009;60(8):1007.

8. Coulter A. Paternalism or partnership? Patients have grown up-and there's no going back. BMJ. 1999;319(7212):719-20.

9. Elwyn G, Frosch D, Thomson R, Joseph-Williams N, Lloyd A, Kinnersley P et al. Shared decision making: a model for clinical practice. J Gen Intern Med. 2012;27(10):1361-7.

10. Tarn DM, Heritage J, Paterniti DA, Hays RD, Kravitz RL, Wenger NS. Physician communication when prescribing new medications. Arch Intern Med. 2006 166(17):1855-62

11. Planès $S$, Villier $C$, Mallaret $M$. The nocebo effect of drugs. Pharmacol Res Perspect. 2016;4(2):e00208.

12. Brody H, Colloca L, Miller FG. The placebo phenomenon: implications for the ethics of shared decision-making. J Gen Intern Med. 2012;27(6):739-42.

13. Cohen S. The nocebo effect of informed consent. Bioethics. 2014;28(3):147-54

14. Brown WA. Placebo as a treatment for depression. Neuropsychopharmacology. 1994;10(4):265-9 discussion 71-88.

15. Kelley JM, Kaptchuk TJ, Cusin C, Lipkin S, Fava M. Open-label placebo for major depressive disorder: a pilot randomized controlled trial. Psychother Psychosom. 2012:81(5):312-4.

16. Locher C, Frey Nascimento A, Kirsch I, Kossowsky J, Meyer A, Gaab J. Is the rationale more important than deception? A randomized controlled trial of open-label placebo analgesia. Pain. 2017;158(12):2320-8.

17. Carvalho C, Caetano JM, Cunha L, Rebouta P, Kaptchuk TJ, Kirsch I. Openlabel placebo treatment in chronic low back pain: a randomized controlled trial. Pain. 2016;157(12):2766-72.

18. Barsky AJ, Saintfort R, Rogers MP, Borus JF. Nonspecific medication side effects and the nocebo phenomenon. JAMA. 2002;287(5):622-7.

19. Ende J, Kazis L, Ash A, Moskowitz MA. Measuring patients' desire for autonomy: decision making and information-seeking preferences among medical patients. J Gen Intern Med. 1989:4(1):23-30.

20. Horne R, Weinman J, Hankins M. The beliefs about medicines questionnaire: the development and evaluation of a new method for assessing the cognitive representation of medication. Psychol Health. 1999;14(1):1-24.

21. Busner J, Targum SD. The clinical global impressions scale: applying a research tool in clinical practice. Psychiatry (Edgmont). 2007:4(7):28-37.

22. Colagiuri B, Zachariae R. Patient expectancy and post-chemotherapy nausea: a meta-analysis. Ann Behav Med. 2010;40(1):3-14.

23. Silvestri A, Galetta P, Cerquetani E, Marazzi G, Patrizi R, Fini M, et al. Report of erectile dysfunction after therapy with beta-blockers is related to patient knowledge of side effects and is reversed by placebo. Eur Heart J. 2003;24(21):1928-32.

24. Schoene-Seifert B. Beware of Nocebo-paternalism: pitfalls of tailored nondisclosure. Am J Bioeth. 2017;17(6):56-8.

25. Fortunato JT, Wasserman JA, Menkes DL. When respecting autonomy is harmful: a clinically useful approach to the Nocebo effect. Am J Bioeth. 2017:17(6):36-42.

26. Miller FG, Colloca L. The placebo phenomenon and medical ethics: rethinking the relationship between informed consent and risk-benefit assessment. Theor Med Bioeth. 2011:32(4):229-43.

27. Wells RE, Kaptchuk TJ. To tell the truth, the whole truth, may do patients harm: the problem of the nocebo effect for informed consent. Am J Bioeth. 2012;12(3):22-9.

\section{Publisher's Note}

Springer Nature remains neutral with regard to jurisdictional claims in published maps and institutional affiliations. 